\title{
Solvent Radiolysis Product Production using Preparative Chromatography
}

\author{
Kyle Wesley Rigg
}

August 2019

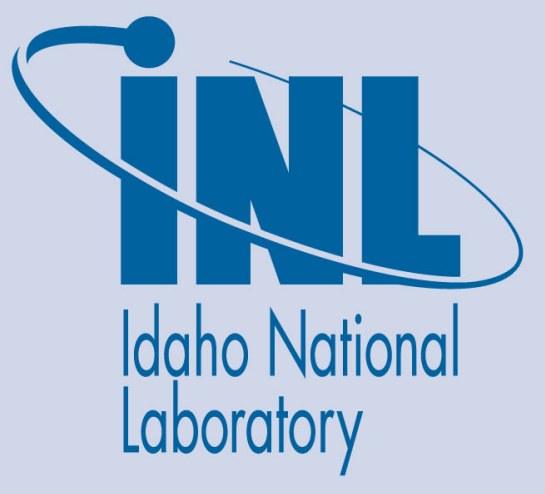

The INL is a U.S. Department of Energy National Laboratory operated by Battelle Energy Alliance 


\title{
Solvent Radiolysis Product Production using Preparative Chromatography
}

\author{
Kyle Wesley Rigg
}

\author{
August 2019 \\ Idaho National Laboratory \\ Idaho Falls, Idaho 83415 \\ http://www.inl.gov \\ Prepared for the \\ U.S. Department of Energy \\ Under DOE Idaho Operations Office \\ Contract DE-AC07-05ID14517
}




\title{
Solvent Radiolysis Product Production using Preparative Chromatography
}

\author{
Kyle W. Rigg, Christopher A. Zarzana, Gary S. Groenewold
}

\section{Impact}

- Enable a quantitative understanding of effects of radiation during used nuclear fuel separations

Critical for modeling separation performance

- Accelerate development of more robust, lower cost fuel cycles by enabling a fundamental understanding of the effects of radiation on organic molecules

Cheaper and more efficient separation methods

\section{Background and Motivation}

- Molecules used to separate used nuclear fuel degrade in the presence of intense radiation, which reduces the separation efficacy over time.

- Standards of these degradation products are required to collect data needed for process modeling and to understand the fundamental radiolysis of fuel cycle ligands

- Synthesis of the individual compounds requires significant time and money

- .Instead of having these bi-products synthesized individually, they can be made with radiolysis and separated with preparative-scale liquid chromatography in $\mathrm{mg}$ to g yields.

- Faster and less expensive method of obtaining degradation products than synthesis.

\section{Research Objective}

- $\quad$ Develop facile, low-cost methods to produce fuel cycle ligand degradation products using radiolysis and preparative liquid chromatography.

- $\quad$ Optimized separation methods are critical to reducing the overall cost of the degradation products produced.

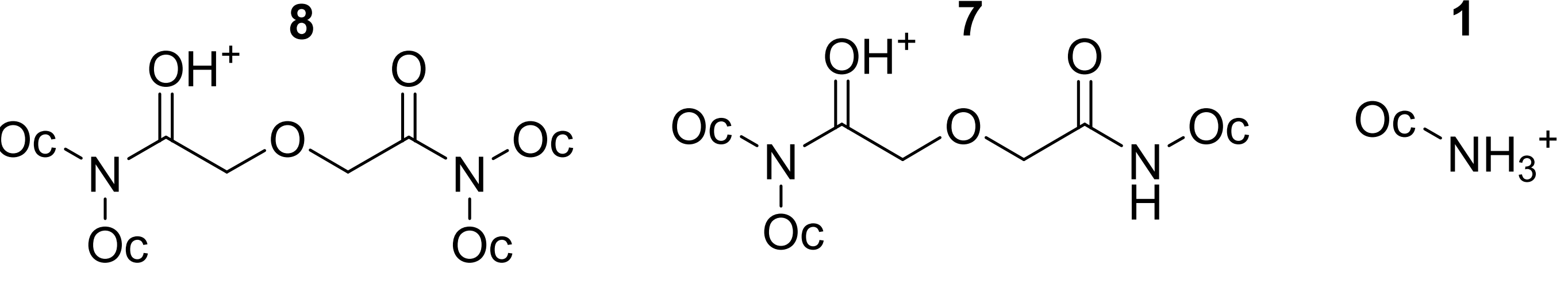

$$
\begin{aligned}
& \mathrm{Oc}_{{ }_{N}} \mathrm{OH}_{\mathrm{N}} \mathrm{H}_{\mathrm{OH}}^{\mathrm{O}} \begin{array}{l}
\mathrm{m} / \mathrm{z}=581.562 \\
\mathrm{TODGA}
\end{array} \\
& \text { Oc }
\end{aligned}
$$

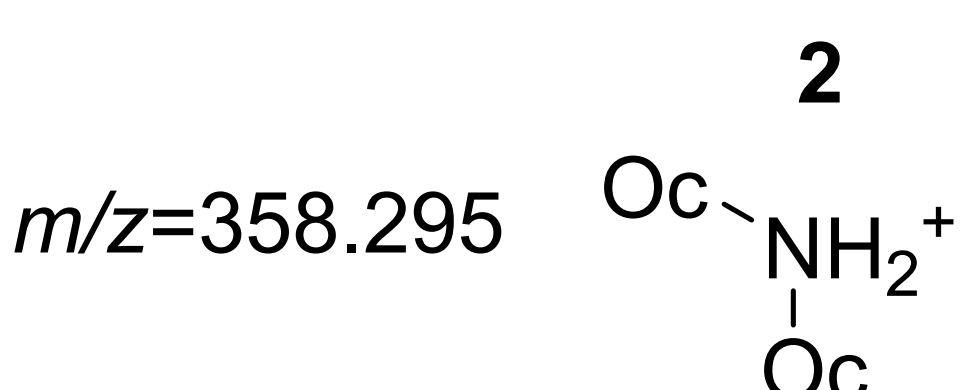

$$
\begin{aligned}
& \mathrm{Oc}^{2} \mathrm{O}_{\substack{1 \\
\mathrm{O}^{\prime}}} \mathrm{OH}^{+} \\
& \mathrm{Oc}_{N_{1}^{1}}^{\mathrm{O}} \\
& 4 \\
& \mathrm{OH}^{+} \\
& \mathrm{Oc}_{\mathrm{N}^{-}} \mathrm{NOH} \\
& \text { Oc }
\end{aligned}
$$

\section{Approach}

$m / z=270.279$ $m / z=300.290$
- Utilize analytical scale liquid chromatography and mass spectrometry to develop optimized separation methods that can be then be scaled up to preparative scale.

- Evaluate methanol as an alternative mobile phase to reduce overall cost

- Determine optimum column chemistry

\section{Experimental Results}

- A standard procedure for method development for complex mixtures using HPLC was created

- Developed approach for correlating deg product retention time with stationary phase and eluent chemistry based on the functional groups present in the deg products

- At low concentrations of the organic component in the eluent, $\mathrm{H}_{2} \mathrm{O} / \mathrm{CH}_{3} \mathrm{CN}$ is significantly more effective compared to $\mathrm{H}_{2} \mathrm{O} / \mathrm{CH}_{3} \mathrm{OH}$, consistent with the more organophilic nature of acetonitrile are the organic/less polar components of the effluent mixtures.

- As the organic composition of the effluent approaches $100 \%$ the two mobile phase approach similar strengths.

- Column stationary phases with a high capacity for hydrogen accepting capacity showed decreasing retention time differences in comparisons of the two mobile phases, compared to those with lower hydrogen accepting capacity increased.

- Mixtures containing a wide range of polar and non-polar compounds can be efficiently separated using the Polar $\mathrm{C} 18$ and EVO $\mathrm{C} 18$ by Phenomenex $\mathrm{HPLC}$ columns in under 10 minutes using either $\mathrm{H}_{2} \mathrm{O} / \mathrm{CH}_{3} \mathrm{CN}$ or $\mathrm{H}_{2} \mathrm{O} / \mathrm{CH}_{3} \mathrm{OH}$

- The latter eluent is preferred due to the cost of acetonitrile.

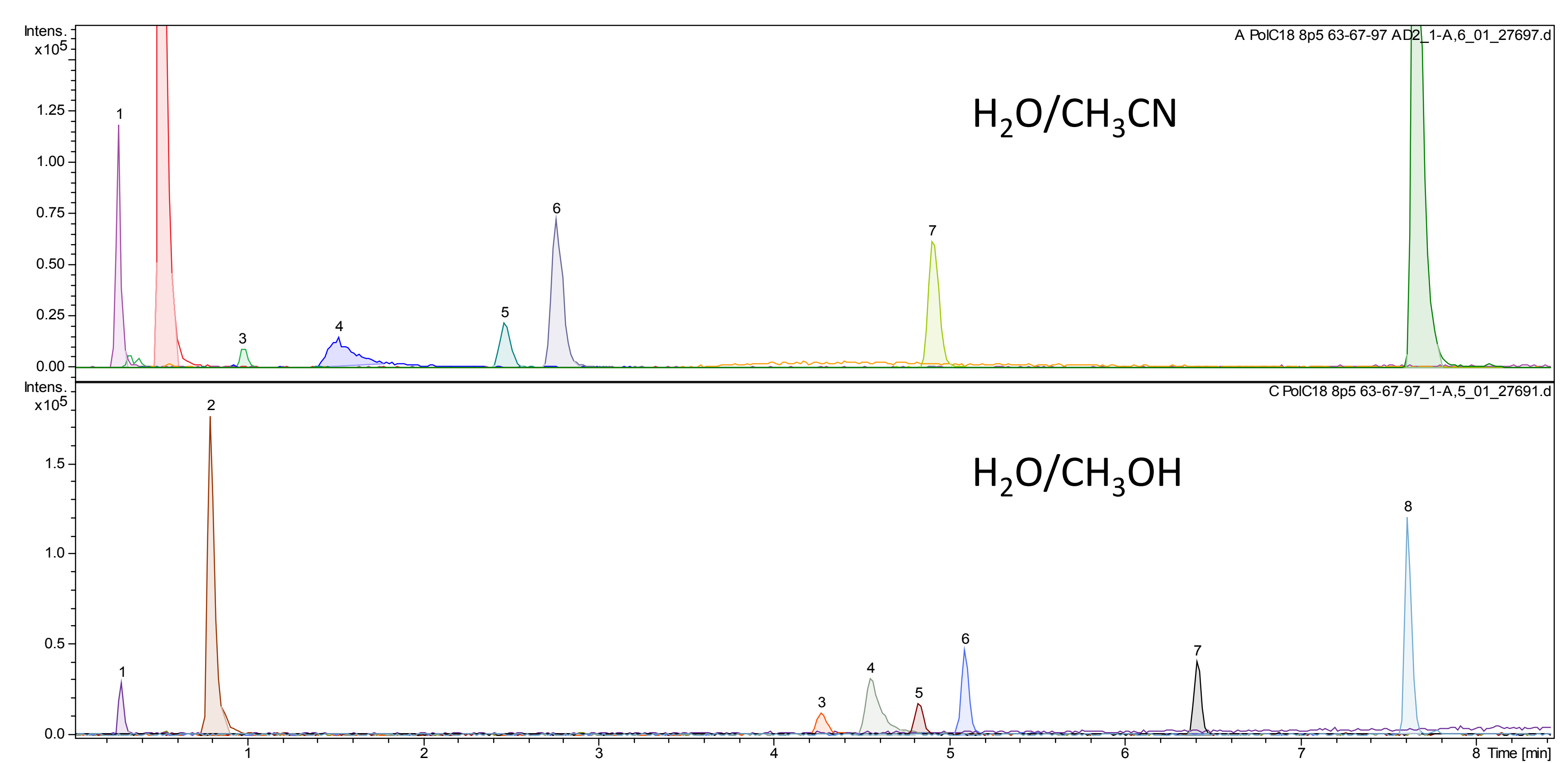

\section{Conclusion and Prospects}

- Methanol is a suitable mobile phase to replace acetonitrile - $\quad$ Reduces cost of the separation by a factor of 4 A robust methodology was developed enabling efficient identification of HPLC separations methodology compatible with complex mixtures of organic degradation products formed from radiolysis of extractant compounds used in fuel cycle separations

- The approach for optimizing compound separation can easily be applied to data sets generated from other complex mixtures as compounds with varying polarity and functional groups interacting with different stationary and mobile phases.

\section{Acknowledgements}

- Work supported through the INL Laboratory Directed Research\& Development (LDRD) Program and the Office of Science Science Undergraduate Laboratory Internship (SULI) program under DOE Idaho Operations Office Contract DEAC07-05ID14517. 